\title{
Mística e Psicanálise: Uma INTROdução, de FReUd a LACAN
}

\author{
ARAÚJO, Ricardo. Experiência mística e psicanálise. São Paulo: Loyola, 2015.
}

Bruno Albuquerque ${ }^{1}$

Tendo se dedicado a investigar a complexa história de (des)encontros entre psicanálise e religião ${ }^{2}$, Ricardo Araújo se lançou a uma nova empreitada: abordar o complexo tema da experiência mística a partir do referencial teórico-clínico psicanalítico. Rejeitando de início tanto o espiritualismo quanto o psicologismo como reducionistas, o autor afirma que a experiência mística "tem lugar no aparelho psíquico dos crentes, donde a legitimidade de uma abordagem psicanalítica da mesma" ${ }^{3}$ (ARAÚJO, 2015, p.7). O pequeno e despretensioso livro se configura como uma introdução ao tema, mas pode surpreender o leitor não apenas por sua consistência teórica, mas principalmente pela precisão clínica com a qual o autor traça distinções claras entre o campo da mística e o campo da psicose.

Ao longo da obra, Araújo retoma vários autores que se dedicaram a abordar a experiência mística ao longo da história da psicologia, da psiquiatria e da psicanálise. O primeiro deles foi William James (1902/1995), que inaugurou o campo

1 Doutorando em Ciência da Religião (PPCIR-UFJF). Mestre em Psicanálise (PGPSA/UERJ). Psicólogo (IP-UERJ). Psicanalista em formação no Corpo Freudiano Escola de Psicanálise - Seção Rio de Janeiro, onde coordenou o grupo de estudos "Psicanálise e religião" (2015-2016). Membro do grupo de pesquisa "Apophatiké: estudos interdisciplinares em mística" (UFF/PUC-Rio). Rua Hermenegildo de Barros, 27, $2^{\circ}$ andar, Santa Teresa, 20241-040, Rio de Janeiro, RJ. (21) 98643-4724. brunopintodealbuquerque@gmail.com.

2 Refiro-me aqui ao livro Deus analisado: os católicos e Freud - A recepção da crítica freudiana da crença religiosa pela Igreja Católica (ARAÚJO, 2014), no qual o autor mostra como a história da relação entre psicanálise e catolicismo de certo modo revela as múltiplas possibilidades de interação entre psicanálise e religião. De uma recusa inicial, seguiu-se uma generosa abertura, que posteriormente gerou certo equilíbrio, mas que depois desembocou numa indiferença contrastante com a apaixonada oposição inicial. Assim, o autor decide se posicionar a favor de um diálogo entre psicanálise e religião sem a perspectiva de síntese. A esse respeito, pode interessar ao leitor também a resenha Psicanálise e religião: uma história de muitos (des)encontros (ALBUQUERQUE, 2016).

${ }^{3}$ Quanto a este ponto, o autor parece se alinhar à posição de Lacan expressa no seminário $\mathrm{A}$ ética da psicanálise, onde o psicanalista francês sustenta que a fé religiosa não pode se esquivar do exame científico: "[...] há um certo paradoxo em excluir praticamente do debate e do exame das coisas termos e doutrinas que foram articulados no campo próprio da fé, com o pretexto de que pertenciam a um âmbito reservado aos fiéis" (LACAN, 1959-1960/2008, p.205). Para o mestre parisiense, o que se articula em termos próprios no campo da experiência religiosa interessa também ao analista: "[...] pertencem a nosso exame e até mesmo requerem, em seu registro próprio e em seu modo de expressão, toda a nossa atenção" (LACAN, 1959-1960/2008, p.206). 
epistemológico da psicologia da religião com o livro As variedades da experiência religiosa. Diversos autores que se debruçaram sobre o estudo da mística sentiram a necessidade de distinguir os fenômenos místicos propriamente ditos dos que são chamados fenômenos paramísticos, com os quais frequentemente a mística é identificada e que, não obstante, são criticados tanto por psicólogos e psiquiatras quanto pelos grandes mestres espirituais, os quais advertem que frequentemente são enganos que podem, inclusive, perturbar a experiência espiritual autêntica. Nesse sentido, Araújo considera a mística como "uma vivência de ultrapassagem dos limites do eu acompanhada do sentimento gozoso de comunhão com o todo circundante identificado ao divino" (ARAÚJO, 2015, p.10).

No que se refere à abordagem propriamente psicanalítica da experiência mística, ela comparece na própria obra freudiana, especialmente no debate entre Sigmund Freud e Romain Rolland sobre o sentimento oceânico. Em O mal-estar na cultura, Freud interpretou este sentimento de união com algo ilimitado como uma regressão a um estágio infantil no qual uma separação clara entre o eu e o mundo externo ainda não havia sido delimitada. $\mathrm{Na}$ última anotação de suas Obras completas, Freud abordou a questão sob outro ângulo, situando topologicamente a experiência mística como uma "obscura autopercepção do reino exterior ao eu, do isso"” (FREUD, 1941[1938]/2006). É nessa direção que Araújo chama a atenção para aquilo que foi considerado como uma inesperada aproximação entre mística e psicanálise, ou seja, que ambas possibilitam o acesso a uma dimensão que escapa à consciência.

Duas vertentes da linguagem mística se sobressaem: por um lado, há uma longa tradição que associa o encontro entre o humano e o divino com o encontro amoroso e sexual entre o homem e a mulher na noite de núpcias; por outro lado, a experiência mística é descrita também numa referência à vivência do bebê acalentado pelo amor da mãe. Numerosos trechos bíblicos fazem uso dessas metáforas para descrever a relação entre Deus e seu povo. Os místicos frequentemente recorrem a essas imagens para descrever suas experiências, como foi o caso de Santa Teresa

\footnotetext{
${ }^{4}$ A Edição Standard Brasileira das Obras Psicológicas Completas de Sigmund Freud adota o termo "ego" para o termo alemão Ich e "id" para Es, mas as traduções mais fidedignas são respectivamente "eu" e "isso".
}

214 Psicanálise \& Barroco em revista | v.16, n. 01 | julho de 2018 
d'Ávila e São João da Cruz, aos quais Lacan fez honrosas referências ${ }^{5}$. Cada uma dessas vertentes da mística, contudo, favoreceu também dois tipos principais de objeções que questionam sua autenticidade e validade no que tange à saúde mental daquele que a experimenta.

Por um lado, o caráter erótico da experiência mística levantou a suspeita de que esta seria uma forma substitutiva e neurótica de satisfação sexual ${ }^{6}$. De fato, não é incomum que a erotização da relação amorosa com a divindade esteja atrelada a uma perturbação da devoção religiosa ${ }^{7}$. Entretanto, isto não necessariamente significa que toda experiência mística seja neurótica. Com efeito, há pelo menos três reações diferentes à interpretação sexual da mística: considerar que os místicos fazem uso metafórico do vocabulário erótico, nupcial e amoroso porque o que vivenciam extrapola muito aquilo que é possível exprimir através da linguagem (James), reconhecer a natureza sexual da experiência mística recusando a ideia de que esta dimensão libidinosa desqualifique a vivência em questão (Vergote) ou considerar que a experiência mística não é sexual, pois escapa à linguagem e aponta para um gozo Outro mais além - ou aquém - do sexual, anterior à castração simbólica (Lacan).

Por outro lado, a alusão à dimensão materna fez com se desconfiasse de que, embora considerados pelas religiões como o ápice da maturidade na vida espiritual, os fenômenos místicos remontem à indiferenciação entre o eu e a mãe, o que aproximaria a mística do campo da psicose ${ }^{8}$. Realmente, numerosos delírios paranoicos possuem uma temática religiosa, e não são poucos os psicóticos que se

\footnotetext{
${ }^{5}$ Por exemplo, no Seminário Mais, ainda, Lacan se refere à mística como "algo de sério, sobre o qual nos informam algumas pessoas, e mais freqüentemente mulheres, ou bem gente dotada como são João da Cruz" (LACAN, 1972-1973/2008, p.81).

${ }^{6}$ Dentre os autores que sustentaram esta posição, cabe destacar Lemesle, Leuba, Janet, Breuer, Reich, Marie Bonaparte, Herbert Moller e Guillaume Han.

${ }^{7}$ Tal foi o caso, por exemplo, do Conde Zinzendorf, cuja obra foi analisada por Oskar Pfister, pastor luterano e psicanalista, com quem Freud se correspondeu durante três décadas. Freud citou o artigo de Pfister em Psicologia das massas e análise do eu: "Pfister, em sua Frömmigkeit des Grafen von Zinzendorf, forneceu um exemplo extremamente claro e certamente não isolado de quão facilmente até um intenso vínculo religioso pode converter-se em ardente excitação sexual" (FREUD, 1921[2006], p.150).

${ }^{8}$ Alguns dos autores que sustentaram esta posição foram, por exemplo, Fernidand Morel, Otto Rank e Franz Alexander. Também Catherine Clément e Sudhir Kakar (1997) parecem adotar esta opinião. Em seu livro escrito em conjunto, A louca e o santo, esses psicanalistas investigaram as histórias da francesa Madeleine e do indiano Ramakrishna. Embora expressassem vivências semelhantes, a primeira foi considerada louca e o segundo, santo.
} 
referem a Deus como representante de sua desmedida aspiração à totalidade ${ }^{9}$. Na linha de autores como James e Lacan, entretanto, Araújo sustenta que é possível diferenciar uma experiência mística autêntica de um surto psicótico ${ }^{10}$. Parece-me que a principal originalidade da obra que apresento consiste na indicação de 16 elementos que possibilitam um discernimento entre mística e psicose, dentre os quais destacarei alguns.

Enquanto o psicótico pode se referir a Deus como um objeto de cuja posse ele goza, sem tolerar sua ausência, o místico reconhece em Deus um Outro livre e independente com quem deseja unir-se no amor e cujas aparentes ausências aceita com serenidade. Assim, "o verdadeiro místico se posiciona a partir de sua castração simbólica, isto é, da sua condição de ser em falta, ao passo que o psicótico, pseudomístico, se caracteriza pela rejeição dessa mesma castração" (ARAÚJO, 2015, p.56). O surto psicótico, por outro lado, impõe-se de maneira invasiva e incontrolável, de modo que o psicótico pode se referir a Deus como um Outro ao qual se encontra subjugado, enquanto a experiência mística é desejada pelo sujeito que a ela se dispõe, frequentemente envolvendo-se com a meditação ou a oração para alcançar buscar ativamente uma maior intimidade com Deus. Além disso, o psicótico atribui um caráter de certeza à sua vivência, enquanto o místico acredita no conteúdo da sua experiência, mas sem excluir a possibilidade da dúvida. Várias outras indicações preciosas são feitas para favorecer um diagnóstico diferencial entre o místico e o psicótico, às quais remetemos o leitor que desejar se aprofundar na matéria.

Por fim, o autor conclui que é importante conhecer e levar a sério as graves e fundadas suspeitas levantadas sobre o valor da experiência mística, mas afirma também que há "critérios satisfatórios para identificar o verdadeiro misticismo, o que nos impede de descartar as vivências místicas como fenômenos puramente patológicos" (ARAÚJO, 2015, p.62). Dessa forma, em sua obra de introdução à abordagem psicanalítica da mística, o autor retoma e sistematiza os pontos principais das contribuições de Freud e Lacan. Nesse sentido, ele se coloca em consonância com a afirmação lacaniana, presente já no seminário As psicoses, sobre a diferença radical entre as experiências de Schreber e São João da Cruz: "Ora, não há

\footnotetext{
${ }^{9}$ Este foi o caso, por exemplo, do juiz e paciente psiquiátrico Daniel Paul Schreber, cujo delírio de conteúdo místico-religioso pormenorizadamente relatado em sua autobiografia foi analisado por Freud (1911/1996).

${ }^{10}$ Outros autores que sustentaram uma posição semelhante foram o padre carmelita Bruno de JésusMarie, o filósofo Henri Bergson, a psicanalista Catherine Parat e o jesuíta Carlos Domínguez Morano.
}

216 Psicanálise \& Barroco em revista | v.16, n. 01 | julho de 2018 
absolutamente nada de comum entre a ênfase que nos é dada de um lado e do outro. Eu diria mesmo que, a respeito do menor testemunho de uma experiência religiosa autêntica, vocês verão toda a diferença" (LACAN, 1955-1956/2008, p.96). 


\section{REFERÊNCIAS}

ALBUQUERQUE, Bruno. Psicanálise e religião: uma história de muitos (des)encontros. Tempo psicanalítico, v.48, n.1. Rio de Janeiro, 2016, pp.232-234.

ARAÚJO, Ricardo Torri de. Deus analisado: os católicos e Freud-A recepção da crítica freudiana da crença religiosa pela Igreja Católica. São Paulo: Loyola, 2014.

. Experiência mística e psicanálise. São Paulo: Loyola, 2015.

CLÉMENT, Catherine. KAKAR, Sudhir. A louca e o santo. Rio de Janeiro: Relume-Dumará, 1997.

FREUD, Sigmund. Notas psicanalíticas sobre um relato autobiográfico de um caso de paranoia [1911]. In: Edição Standard Brasileira das Obras Psicológicas Completas de Sigmund Freud (ESB), v.XII. Rio de Janeiro: Imago, 1996, pp.13-89.

. Psicologia de grupo e análise do ego [1921]. In:

Imago, 1996, pp.77-154.

. O mal-estar na civilização [1930(1929)]. In: . ESB, v.XVIII. Rio de Janeiro:

Imago, 1996, pp.65-148.

. Achados, idéias, problemas [1941(1938)]. In: ESB, v.XXIII. Rio de Janeiro: Imago, 1996, pp.317-318.

JAMES, William. As variedades da experiência religiosa: um estudo sobre a natureza humana [1902]. São Paulo: Cultrix, 1995.

LACAN, Jacques. O seminário, livro 3: as psicoses [1955-1956]. 2. ed. Rio de Janeiro: Zahar, 2008. 2008.

. O seminário, livro 7: a ética da psicanálise [1959-1960]. 2. ed. Rio de Janeiro: Zahar, . O seminário, livro 20: mais, ainda [1972-1973]. Rio de Janeiro: Zahar, 2008. 
Recebido em: 02-04-2018

Aprovado em: 20-04-2018

(C) 2018 Psicanálise \& Barroco em revista

http://www.seer.unirio.br/index.php/psicanalise-barroco/index

revista@psicanaliseebarroco.pro.br

Programa de Pós-Graduação em Memória Social — UNIRIO.

Memória, Subjetividade e Criação.

http://www.memoriasocial.pro.br/proposta-area.php 